\title{
The Impact of Learning with Laptops in 1:1 Classes on the Development of Learning Skills and Information Literacy among Middle School Students
}

\author{
Ornit Spektor-Levy and Yael Granot-Gilat \\ School of Education, Bar Ilan University, Ramat-Gan, Israel
}

\author{
ornitsl@gmail.com yaelbambule@gmail.com
}

\begin{abstract}
The goal of this study was to examine the impact of a one-to-one program on the implementation of learning skills, information literacy, and the usage of computerized tools among students. These skills are part of the demands placed upon schools to develop 21st century competencies. Seventh and ninth grade students participated in this study $(\mathrm{N}=181)$. One group had routinely studied in 1:1 classes with personal laptops (Intervention group) and others studied in regular classes with no ICT (Comparison group). The research tool consisted of a complex, computerbased learning task. Completion of the task required implementation of skills such as information retrieval, information evaluation, reading comprehension, information processing and representation, and knowledge presentation. Findings indicated that students from 1:1 classes performed significantly better than students from the comparison group. Their higher competencies were manifested in the final score as well as in skills such as organizing information in a table, evaluating information and its reliability, quality of argumentation, and representation and presentation of knowledge while using computerized tools. These results indicate, on the practical level, the positive effect of learning with personal laptops and routinely available ICT on students' achievements and competencies.
\end{abstract}

Keywords: one-to-one classes, $21^{\text {st }}$ century skills, information literacy, ICT.

\section{Introduction}

In recent decades new standards have formulated new reforms that reflect the overall goal of preparing students for the requirements of the 21 st century knowledge-based society. Nowadays, educators are required to redefine educational goals and integrate technology into the school curriculum (Swan, Van 'T Hooft, Kratcoski, \& Schenker, 2007).

Material published as part of this publication, either on-line or in print, is copyrighted by the Informing Science Institute. Permission to make digital or paper copy of part or all of these works for personal or classroom use is granted without fee provided that the copies are not made or distributed for profit or commercial advantage AND that copies 1) bear this notice in full and 2) give the full citation on the first page. It is permissible to abstract these works so long as credit is given. To copy in all other cases or to republish or to post on a server or to redistribute to lists requires specific permission and payment of a fee. Contact Publisher@InformingScience.org to request redistribution permission.

The integration of technology in schools has evolved from desk-top computers to laptops (1:1); from computers used in a specific lesson to computers used anytime anywhere (24/7). Despite the many ways in which computers can be accessed within schools (e.g., in labs, libraries, or on shared carts), teachers and students still report using computers in

\section{Editor: Janice Whatley}

An earlier, shorter version of this paper was presented at the Chais conference 2012, in Raanana, Israel, and included in Y. Eshet-Alkalai, A. Caspi, S. Eden, N. Geri, Y. Yair, \& Y. Kalman (Eds.), Proceedings of the Chais conference on instructional technologies research 2012: Learning in the technological era. Raanana: The Open University of Israel. http://www.openu.ac.il/research center/chais2011/papers.html 
school for only a fraction of the time each day (Bebell \& Kay, 2009; Bebell, Russell, \& O'Dwyer, 2004; Russell, Bebell, O’Dwyer, \& O'Connor, 2003). Many observers theorize that the disjuncture between the dramatic increase in the presence of computers in schools and the relatively unchanging degree of use is due, in part, to the fact that student-to-computer ratios have not yet reached the stage where the technology is ubiquitous (Bebell \& Kay, 2009; Bull, Bull, Garofolo, \& Harris, 2002; Rockman et al., 1998). Yet there is a dramatic increase around the world of initiatives that provide laptop computers to students and teachers (1:1) aimed at reaching the pervasiveness of computers in schools.

Despite the growing interest in 1:1 computing, there is a lack of sufficient, sustained, large-scale research and evaluation that focuses on teaching and learning in these intensive computing environments (Bebell \& Kay, 2010). Specifically, there is a lack of evidence that connects the use of technology in these 1:1 settings with measuring student achievement. This is a particularly salient issue in light of the high cost of implementing and maintaining 1:1 laptop initiatives and the current climate of educational policy (Bebell \& Kay, 2010). Thus, the aim of the study described here was to evaluate the impact of learning with laptops in 1:1 classes on the development of learning skills and information literacy among middle school students.

\section{Integrating Technology in Education}

Information and Communication Technology (ICT) produces changes that require the education system to respond, to cope, and even to change (Fullan, 2001; Salomon, 2000). Adapting the education system to the 21 st century is a process whose objective leads to the presence of an innovative pedagogy in the schools while employing Information and Communication Technology (ICT). The transition to a knowledge society compels the education system to innovate and change at the national and municipal policy-making levels, as well as at the local level, including the schools and the parents (Mioduser, Nachmias, Forkush, \& Tubin, 2003).

In a traditional learning system that does not use modern technology, the teacher has great difficulty addressing all the students in a classroom effectively and in an equal manner (Katz \& Offir, 1996). In an ICT environment the personal laptop computer offers unique and powerful abilities to allow each student to work at his or her own pace, personal mentoring combined with feedback responses, software that improves learning, and support through peer collaboration (Dunleavy, Dexter \& Heinecke, 2007). In this way a teacher can work in a heterogeneous classroom while addressing its inherently different levels of students without the need for delaying or slowing down the pace of the other students.

Education systems around the world have succeeded in understanding that they must prepare for the 21 st century in various ways to bring the learner through the process to becoming a graduate who is fit for the work and tasks of the century in which we live. Thus, school leavers must adapt to the constantly changing reality, complex systems that require skills of various kinds, and a growing requirement for originality, ingenuity, self-discipline and management, as well as problem solving capabilities.

The Israeli Ministry of Education's National ICT Program (Ministry of Education, 2012) is aimed at investing in ICT infrastructure in schools, so as to provide students and teachers with an advanced and optimal teaching and learning environment. This environment - Smart Classes - is to include Internet connectivity, laptop computers for the teachers, a ceiling-mounted projector in the classroom, and a computer-student ratio of 1:5. These learning environments provide tools that allow more accessibility to contemporary, media-rich, digital content that embraces flexible teaching and learning processes. Hence, the Ministry of Education understands that it is also essential to invest in the professional development of the educators, so as to promote technology 
integration in routine teaching and learning, and in order to ensure the success of the program (Ministry of Education, 2012).

\section{Models of ICT in Schools around the World}

Various models of learning with computers can be found around the world. ICT models using small-scale student populations are referred to as Islands of Innovation (Forkosh-Baruch, Nachmias, Mioduser, \& Tubin, 2005). Diversely, some schools have adopted ICT widely, embracing most of the students and teachers at the school, in a model that is referred to as Schoolwide Implementation, for example, schools where the entire school population is in possession of personal laptops, used by the students and teachers to work in the various subject areas (ForkoshBaruch et al., 2005). Even among the School-wide Implementation models it is possible to find a myriad of variations: some use laptops that are stored on carts and transferred between classrooms as needed; others, such as 1:1 programs, integrate computers in intensive ways whereby every student and teacher has a personal laptop, and the classrooms in the school are equipped with a projector plus a screen, as well as the means for darkening the room. Computer integrated learning takes place in all the subject areas, and the students and teachers take their personal computers home with them at the end of the school day and return with them the next day.

Laptops allow the teacher to be a facilitator and to encourage the students to explore and solve problems on their own by looking for information and collaborating among themselves, leading to heightened student interpersonal skills and critical thinking as well (Warschauer, 2005-2006, 2008). However, most of the studies have found it difficult to demonstrate changes in student achievements on knowledge tests and on international standards tests (For example: Shapley et al., 2009; Silvernail \& Buffington, 2009; Weston \& Bain, 2010).

\section{Learning Skills, Information Literacy and 21st Century Skills}

One of the tasks awaiting the education system in this information-rich age is to educate the learner to derive the anticipated benefits from the information and to shield against the dangers inherent in it. Another goal is to educate the learner to acquire learning skills that enable him or her to locate information, to process it, and present new knowledge (Spektor-Levy, Eylon, \& Scherz, 2009). The field that deals with searching and processing information is called Information Science or Information Literacy. Information Literacy is the educated use of information in order to obtain defined knowledge. It is not the outcome of ICT. However, as a consequence of ICT, Information Literacy has gained new meaning. A person's ability to use Information Literacy in order to create and consolidate his or her own required knowledge is as important today, if not more so, than accumulating edited and ready-made knowledge (Ministry of Education, 2012). Twenty-first century skills include competencies such as creative thinking; information and communication literacy (the students will use the technology and the environment in order to communicate and work in cooperation with others, at a distance, with the aim of advancing their studies and helping others); interpersonal relations and self-management (interpersonal skills and cooperative work, independent learning and behavior, flexibility and adaptability, and personal as well as social responsibility); critical thinking, problem solving, and decision-making (Information Literacy or Information Science); technological comprehension; technological concepts and operation (the use of software, using the Internet, online protection, using communication technology) (Ministry of Education, 2012; Mueller, 2009)

\section{Development of Competencies in 1:1 Classes}

Lei \& Zhao (2008) contend that when it comes to the question of what really happens when every student has a laptop and how the laptops are being used in classrooms, current studies provide only general information on "what" and "how much" is used, as well as changes in "what" and 
"how much," while there is a dearth of information on "how" the laptops are being used in teaching and learning practices. Due to the expansion of such initiatives in many countries, it is necessary to question the effectiveness of such learning environments (Kozma, 2003; Penuel, 2006), to characterize the one-to-one learning environments, and to analyze the impact of such environments on students' achievements and other variables (Beresford-Hill, 2000).

Early research and evaluation studies suggest several positive outcomes from 1:1 laptop initiatives, including increased student engagement (Cromwell, 1999; Maine Education Policy Research Institute (MEPRI), 2003; Rockman et al, 1998), decreased disciplinary problems (Baldwin, 1999; MEPRI, 2003), increased use of computers for writing, analysis and research (Baldwin, 1999; Cromwell, 1999; Guignon, 1998; Russell, Bebell, \& Higgins, 2004), and a movement toward student-centered classrooms (Rockman et al, 1998). Baldwin (1999) also documented effects on student behavior at home, e.g., with more time spent on homework. Gulek and Demirtas (2005) compared test scores among students participating and not participating in a voluntary 1:1 laptop program in middle school. A significant difference in test scores was found in favor of students participating in the laptop programme.

This study has researched the effect of intensive, daily use of laptops in school, as part of the routine studies on learning and information literacy skills, by using an assessment tool that was specially developed for the research. The assessment tool is a complex learning task involving the use of a computer while implementing diverse learning skills and Information Literacy competencies such as information retrieval, evaluating information, reading comprehension, information processing, and preparation and presentation of a visual representation in an attractive and clear manner.

\section{Research Questions and Overview}

The uniqueness of the study proposed here is that this research investigates the impact of learning through personal laptops (1:1) at a practical, operational level, in the context of conducting a complex learning task and analyzing it.

To achieve this goal the following research questions were addressed:

To what extent does routine learning with personal laptop computers affect the acquisition and implementation of learning skills and other components of Information Literacy among middle school students?

To what extent do students who routinely study with personal laptop computers have mastery of the learning skills and other components of Information Literacy compared with students who study in classes without ICT?

This study explores these issues and describes an innovative educational project that started in 2006 in Israel and took place in four schools (three elementary schools (one of which includes both elementary and middle school) and one middle school) in two small urban communities (i.e., covering grades 5-9). All students and all teachers were provided with personal laptop computers for class and home use. The teaching and learning has been routinely taking place in an ICTsaturated environment and Virtual Learning Campus (VLC). The study described here took place within two of the four schools that participated in the project. 


\section{Methodology}

\section{Sample}

The research sample included 181 students aged 13-15, studying in middle school: 86 boys and 95 girls, 88 seventh-graders (48.62\%; aged 13 years), 93 ninth-graders (51.38\%; aged 15 years) (Table 1). All of the students $(\mathrm{N}=181)$ study at two middle schools, in two different local authorities, in urban communities. All the students come from a high socio-economic background, according to the local authority reports. The students attending one of the middle schools $(\mathrm{N}=81)$ study the traditional way without laptops, being exposed to computers only several times a year when they are taken for a lesson in the school's computer lab. The school computer lab comprises about 40 computers and serves the whole school, which numbers approximately 1,600 students. The lab is accessible only after prior coordination with the person in charge of it. School computer lessons are rare. This group will be referred to as the comparison group. At the second middle school, students own personal laptops, which were purchased by parents with the aid of subsidies, as part of an initiative by the local municipal authority. Ninth-graders have been studying with laptops for four years. Each student studies with his or her own personal computer and takes it home at the end of the school day. This group of students will be referred to as the intervention group $(\mathrm{N}=100)$.

Table 1: Distribution of the research participants by study groups and age level

\begin{tabular}{|c|c|c|c|}
\hline \multirow{2}{*}{$\begin{array}{c}\text { Gender } \\
\text { \& grade }\end{array}$} & Total & \multicolumn{2}{|c|}{ Research Groups } \\
\cline { 3 - 4 } & & Comparison & Intervention \\
\hline Boys & $86(47.52 \%)$ & 38 & 48 \\
\hline Girls & $95(52.48 \%)$ & 43 & 52 \\
\hline Total & 181 & 81 & 100 \\
\hline \hline Grade Level & & & \\
\hline 7 th & $88(48.62 \%)$ & 41 & 47 \\
\hline 9 th & $93(51.38 \%)$ & 40 & 53 \\
\hline Total & 181 & 81 & 100 \\
\hline
\end{tabular}

\section{Teaching and learning with personal laptops}

Regarding the intervention group, studying routinely takes place most days of the week using the laptop computers throughout the day, in the one-to-one model. Most of the instructional materials can be found in digital format on a virtual learning campus, so that most of the assignments, outcomes, and assessment tools are submitted via a learning management system (LMS). During the lessons, and because of the availability of ICT tools and a variety of media, students are asked to watch video clips and comment about them; use tools for organizing data and knowledge, such as graphs, figures, tables; and search for information online to promote a common group outcome. 
However, in general, and based on testimonies by the teachers, there is no structured, explicit instruction of skills. In this context, a similar situation exists in the comparison group, where based on testimony of the teachers, there is no explicit instruction of skills.

\section{Research tools}

The research included a quantitative assessment tool: a complex learning task which the students worked on using the computer. The assignment was developed specifically for this study. The assignment dealt with the subject of "Israel's water crisis". A time limit was set for the students to complete the assignment (90 minutes) and submit it. The assignment required the students to locate information online about solutions to the water crisis in Israel, choose one of the solutions, and create a poster or leaflet explaining why, in their opinion, this was the most suitable solution. The assignment consisted of using a computer while implementing diverse skills such as information retrieval, selecting information, evaluating information and reliability, reading comprehension, information processing, formulating an argumentative paragraph, preparing a visual representation, and presenting it in a clear and attractive format (a poster or leaflet).

The students in the comparison group carried out the assignment during Science lessons in the school computer lab. The Science teacher and the researcher remained in the classroom during the assignment in case clarification was needed. Any student who did not finish the assignment during the allotted time was required to finish the assignment at home after the lesson and send the completed assignment via email (all students had access to email at home).

The students in the intervention group that had possession of personal laptops carried out the assignment during various lessons, according to requirements of the schedule. The students downloaded the assignment from the school's website or their class's virtual campus, and worked on the assignment using their personal laptops in class. The teacher and the researcher remained in the classroom during the assignment in case clarification was needed and to answer any questions. Students were required to submit the assignment to the school's virtual campus site or to send the completed assignment by email at the end of the lesson.

The submitted assignments were assessed using a detailed rubric that was developed for this study. The rubric refers to every section of students' assignment and specifies various learning skills, components of information literacy, and knowledge.

The assignment's requirements included:

- Reading an information passage.

- Locating sources of information dealing with ways of solving Israel's water shortage.

- Writing an exact and detailed description of the stages of searching for information online.

- Choosing five relevant and reliable sources.

- Choosing one of the information sources - the most appropriate one.

- Providing an explanation of what was taken into consideration in selecting the source of information (professional, reliable, relevant, clear, readable ....)

- Providing a description of content or knowledge - in the student's own words.

- Explaining the advantages and disadvantages of the solution originally presented in the source. Looking for more information on the subject if needed. 
- Preparing a formatted page (a leaflet/poster) to distribute to people in order for them to support the selected solution:

- Writing an argumentative paragraph explaining the student's opinion on the matter.

- Formatting the page with pictures and illustrations (related to the subject) so it will be interesting and attract people to read and be supportive.

- Choosing the appropriate computerized program/tool for designing and preparing the leaflet/poster. Mastering this program.

The analytical rubric specified 14 detailed criteria and three levels of performance for each criterion. The maximum score of the all assignment was 80 . However, when the data was analyzed, we calculated the relative value of the maximum score so that the maximum final score was 100 . For a comparison between the two research groups regarding the different competencies that were evaluated by the complex learning task, each criterion was diagnosed separately with a maximum score of 100.

\section{Validation and Reliability of the Assignment and the Rubric}

In the preliminary stage, a sample of about $15 \%$ of the assignments were checked by the researcher and in parallel by another rater using the rubric. Compatibility and agreement among researchers was checked regarding the assessment of student performance. In cases of disagreement, there was a discussion between the raters for clarification and, if necessary, even by amending the rubric.

For the purpose of validation, the assignment and the rubric were submitted for examination to three researchers in the field of integrating technology in education, to ensure their validity. Only later, after reaching a high agreement (95\%) among the experts, was the rubric completed and became a tool for assessing the quality of task performance by the students. During the validation and while checking the assignments, an effort was made to hide the group affiliation, i.e., whether the task was carried out by students from the intervention or comparison group. But this concealment was not always possible.

Inter-judge reliability was calculated. The level of agreement between the raters for all the items was very high and ranged from $92.9 \%-100 \%$. The average agreement rate was $98.46 \%$. Kappa values for each criterion ranged between $0.47-0.76$ and indicated a good to high agreement between the raters.

Pearson's correlation for evaluation of consistency and reliability was calculated among the raters and was approved as very high. Significant positive correlations of very high intensity were found among the raters: $r=0.95, \mathrm{p}<.01$

The range of the positive correlations between the raters' ratings of the various items was 0.74 0.90 .

Note taking: While the students carried out the complex learning task, the researchers wrote notes regarding special events or phrases that were uttered by the students. These notes were transcribed. The researchers later reread them in order to get a general impression of the students' reactions while working on the assignment.

\section{Findings}

As mentioned above, in order to analyze student performance of the complex tasks, a detailed analytical rubric was developed. To determine whether there was a difference between the comparison and intervention groups in the final score of the task, as well as the level of performance 
of the various criteria, a t-test of independent samples was conducted. The analysis found that there is a significant difference between the comparison group and the intervention group in the final score of the assignments $\mathrm{t}(40)=3.0362, \mathrm{p}<.05$. In other words, the average of the assignment's total scores in the intervention group $(\mathrm{M}=65.95, \mathrm{SD}=7.64)$ was significantly higher than that of the comparison group $(\mathrm{M}=58.65, \mathrm{SD}=7.94)$. Since the maximum score of the assignment was 80 , we calculated the relative value of the averages that were obtained, had the maximum score been calculated as 100 . Thus, the average total score of the comparison group was 73.25 , whereas the average total score of the intervention group was significantly higher: 82.5 (Figure $1)$.

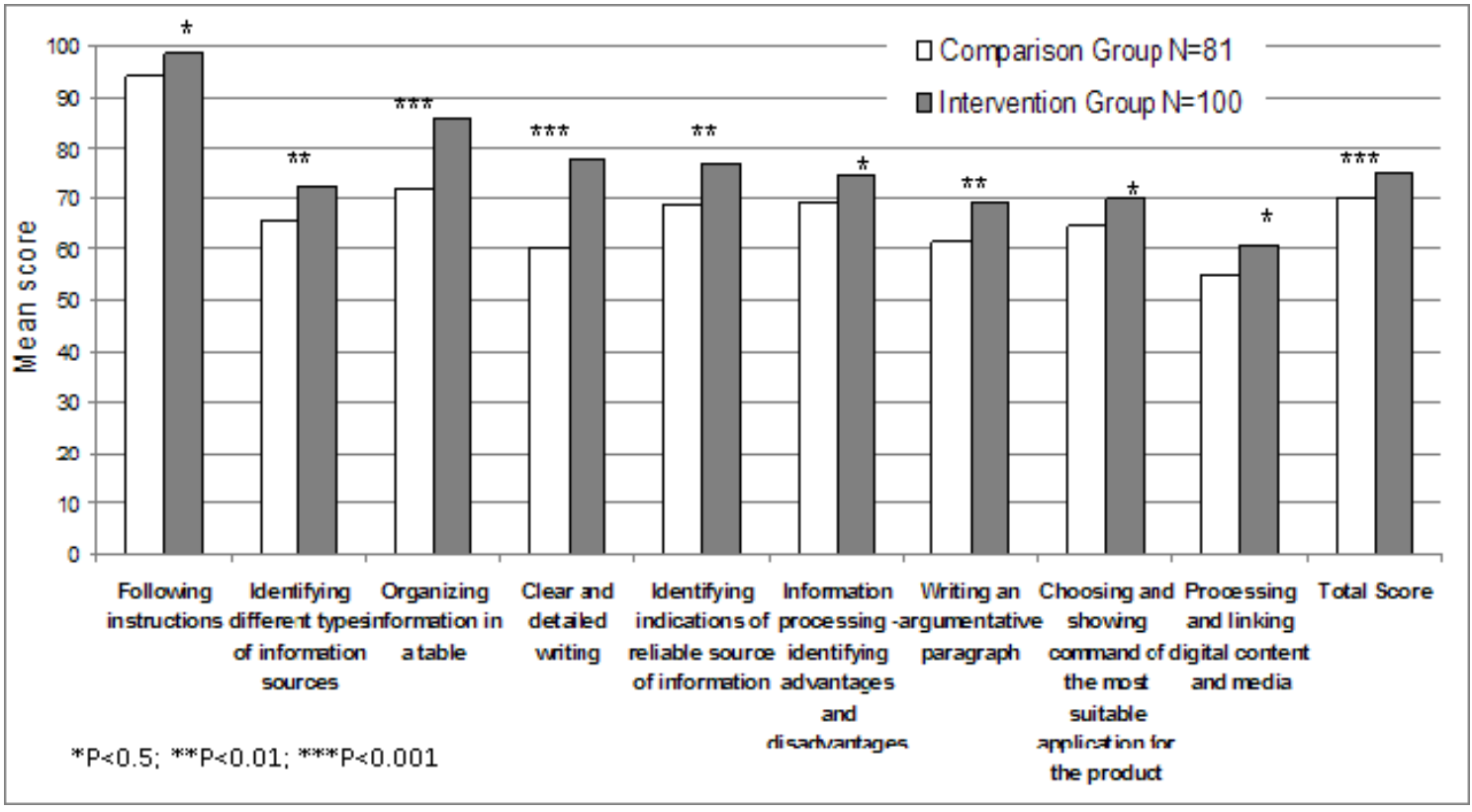

Figure 1: Comparison of students performances $(\mathrm{N}=181)$ in each sample regarding the total score and competencies in which a significant statistical difference was found. Each criterion was evaluated separately, with 100 as maximum score.

Furthermore, the findings reveal nine criteria with significant differences: following instructions; identifying different types of information sources; organizing information in a table; clear and detailed writing; identifying indications of reliable sources of information; information processing-identifying advantages and disadvantages; writing an argumentative paragraph; choosing and showing mastery of the most suitable software application for the product; processing and linking digital content and media. All indicate a significant higher competency of students in the intervention group who study with personal laptops compared with the students studying in the classroom without ICT (Figure 1). In four criteria no significant difference was found between groups: information retrieval, understanding scientific terms, text representation, providing further details.

Next, the intervention and comparison groups were compared according to age level. Figure 2 shows that this comparison, just amongst the seventh-graders, also indicated a significant difference in the average total score in favor of the intervention group. Moreover, seven items and capabilities were found in which the students of the intervention group demonstrated a significantly higher level of performance, as shown in Figure 2. 


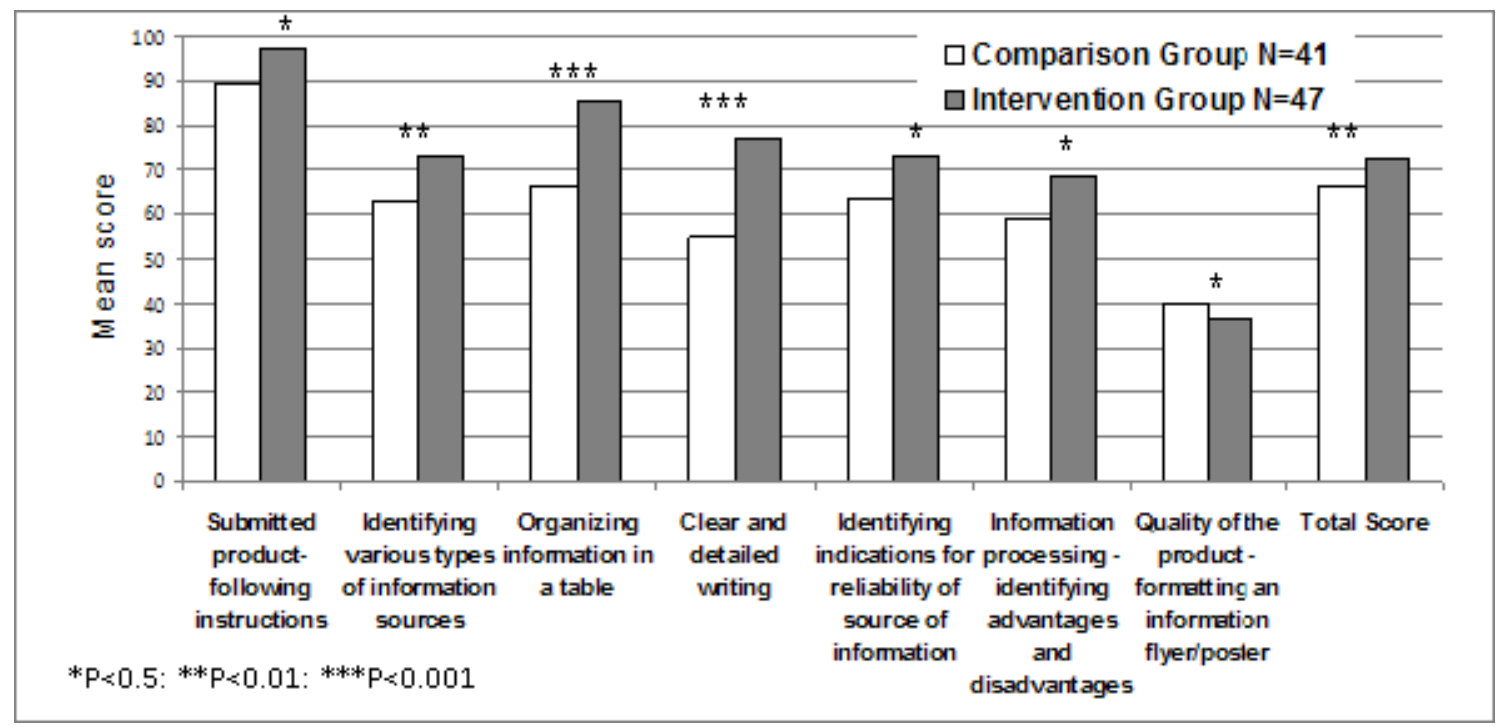

Figure 2: Comparison of students' performances in seventh grade $(\mathrm{N}=88)$ regarding the total score and competencies in which a significant statistical difference was found.

These findings reveal seven criteria with significant differences: following instructions; identifying various types of information sources; organizing information in a table; clear and detailed writing; identifying indications for reliability of sources of information; information processingidentifying advantages and disadvantages. All indicate that students in the intervention group studying with personal laptops demonstrated higher competency than students studying in the classroom without ICT (Figure 2). The findings revealed one criterion in which students from the comparison group performed significantly better than the intervention group, and that is quality of the product-formatting an information leaflet/poster (Figure 2). We will elaborate about it further in the discussion.

Additionally, we compared between the intervention group and the comparison group among the ninth graders. Figure 3 shows that this comparison, just amongst the ninth-graders, also indicated a significant difference in the average total score in favor of the intervention group. Moreover, five items and competencies were found in which the students of the intervention group demonstrated a higher level of performance, as shown in Figure 3.

These findings reveal five competencies with significant differences of performance: organizing information in a table: clear and detailed writing; identifying indications for reliability of source of information; writing an argumentative paragraph; choosing and showing mastery of the most suitable software application for the product. All indicate higher competency among students in the intervention group studying with personal laptops compared with students studying in a classroom without ITC (Figure 3).

While the students carried out the complex learning task, the researchers wrote notes regarding special events or phrases uttered by the. Based on these notes some marked differences were perceived between the two groups in the study. 


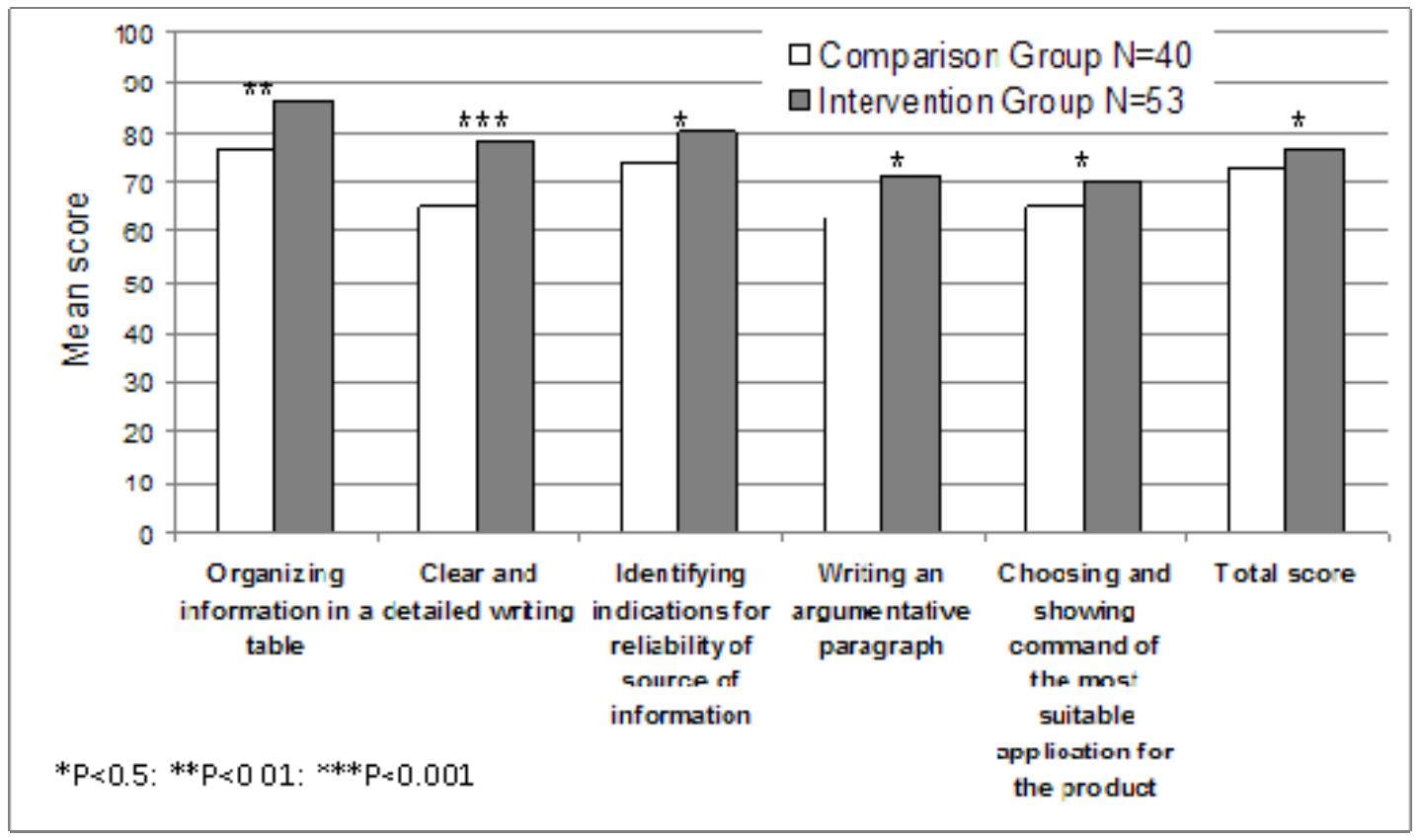

Figure 3: Comparison of performance of ninth grade students $(\mathrm{N}=93)$ regarding the total score and competencies in which a significant statistical difference was found.

\section{The comparison group (no ICT)}

- Problems understanding the basic instructions of working with the computer such as:

- "I don't know how to work on Word, I only have Facebook at home, I just hang around in chats";

- "I don't know how to fix up this table-it's too long".

- The total duration of the work was longer, and sometimes students did not finish the assignments ( 3 seventh-graders and 5 ninth-graders).

- Poor computer tools usage skills-only worked on Word files and PowerPoint presentations.

\section{The intervention group (studying with personal laptops)}

- Technical problems with the computers-students without a computer; transformers that ran out of power and lack of charging areas in the classroom; technical problems with the computers and Internet working slowly. For example:

- "You try working with a computer like ours, and then let's see what happens";

- "It gets stuck all the time, I can't work like this".

- The total duration of work was shorter than in the comparison group, most of the students finished before the allotted time, there were no students who did not complete the assignment.

- High level of computer tools usage skills - students worked simultaneously on multiple websites, with an average of more than three windows running; used the Paint application; listened to music while working. 


\section{Discussion and Conclusions}

A number of advantages emerge from the research literature for the model of teaching and learning using laptops in 1:1 classrooms. However, most of the studies find it difficult to demonstrate changes in students' achievements or heightened quality of teaching and learning (Zucker \& Light, 2009). Most studies about these environments focus on the attitudes of students and teachers and the frequency of use of computers. Very few empirical studies actually examine the students' information competencies and preparing them to acquire 21 st century skills (Warschauer, 2008).

The purpose of this study was to examine the effect of a teaching and learning program with personal 1:1 laptops on students' acquisition and implementation of learning skills and information literacy, and the students' degree of mastery of computerized tools.

By means of the research tool that consisted of a complex, computerized learning task and an analytical checking rubric, this study found significant differences between the actual competencies of students who learn with personal laptops in 1:1 classes and students who learn with no ICT in class. Students from 1:1 classes outperformed significantly better in nine out of 15 subcriteria, and in the total score. Thus, those students realized better learning and information literacy skills. The heightened competencies were reflected in skills such as comprehending instructions; the ability to locate and select information; organizing information in a table; evaluating reliability and credibility of information; distinguishing between sources of information; the quality of writing an argumentative paragraph; and better production of a leaflet/poster using computerized tools.

In the seventh-grade, significant statistical differences were found in six of the 15 sub-criteria, and in the total score in favor of the intervention group that studied with laptops. In one criterion it was the comparison group who performed significantly better: in designing the outcome - a leaflet or poster. The reason for that finding might be that the seventh-graders who study with no ICT were so enthusiastic about the work with computers, that they were more creative and more motivated to design an appealing outcome in comparison to seventh-graders who routinely worked with laptops. Further examination of that point should include interviews with students.

In the ninth grade, significant statistical differences were found in five of the 15 sub-criteria, and in the total score. The differences showed that students who study in 1:1 classes performed better than students who study with no ICT in class.

Thus, ninth grade students who had studied for four years with personal laptop computers, demonstrated statistically significant heightened competencies compared with ninth grade students who studied in a regular classroom without ICT. The heightened competencies were organizing information in a table; evaluating the reliability and credibility of information; quality of writing of the argument; and better production of a poster using computerized tools.

\section{Practical Implications}

The findings of this study are very significant. The findings are indicative not on a declarative level, as are many published studies in 1:1 classes (Penuel, 2006), but on a practical level. Studies that examine development of learning competencies on a practical level in ICT saturated classes are not very common in the literature. Another importance of the study we described here is the fact that its findings reveal the cumulative benefit of teaching and learning in classrooms with intensive ICT and with the use of personal laptop computers. Students who learn with personal laptops for two or four years develop better learning skills and information literacy than students who learn with no ICT. This accumulative effect supports the claims that the investments of resources in 1:1 classes are beneficial in the long run. 
Furthermore, the complex computerized learning task that was presented in this paper and the analytical rubric that was developed to evaluate students' competencies contribute to the growing efforts and attempts to develop scales or measures with established reliability and validity for the evaluation of the effects of laptops on student competencies and understanding.

\section{References}

Baldwin, F. (1999). Taking the classroom home. Appalachia, 32(1), 10-15. Retrieved October 15, 2008, from http://www.arc.gov/index.do?nodeId=1297

Bebell, D., \& Kay, R. E. (2009). Summary of findings from the Berkshire 1:1 laptop program. Paper presented at the Annual Meeting of the National Educational Research Computing Conference. Washington, D. C.

Bebell, D. \& Kay, R. (2010). One to one computing: A summary of the quantitative results from the Berkshire Wireless Learning Initiative. Journal of Technology, Learning, and Assessment, 9(2).

Bebell, D., Russell, M., \& O’Dwyer, L.M. (2004). Measuring teachers' technology uses: Why multiple measures are more revealing. Journal of Research on Technology in Education, 37(1), 45-63.

Beresford-Hill, P. (2000). The laptop computer: Innovation and practice in a time of shifting paradigms. Retrieved June 28, 2008, from http://www.patana.ac.th/Pubs/Papers/LTComputers.pdf

Bull, G., Bull, G., Garofalo, J., \& Harris, J. (2002). Grand challenges: Preparing for the technological tipping point. Learning and Leading with Technology, 29(8), 6-12.

Cromwell, S. (1999). Laptops change curriculum - and students. Education World. Retrieved November 6, 2003, from http://www.education-world.com/a curr/curr178.shtml

Dunleavy, M., Dexter, S., \& Heinecke, W. (2007). What added value does a 1:1 student to laptop ratio bring to technology-supported teaching and learning? Journal of Computer Assisted Learning, 23, $440-452$.

Forkush-Baruch, A., Nachmias, R., Mioduser, D., \& Tubin, D. (2005). "Islands of innovation" and "School-wide implementations": Two patterns of ICT-based pedagogical innovations in schools. Human Technology, 1(2), 202-215.

Fullan, M. (2001). The new meaning of educational change (3rd ed.). New-York: Columbia University, Teachers College.

Guignon, A. (1998). Laptop computers for every student. Education World. Retrieved from http://www.education-world.com/a curr/curr048.shtml

Gulek, J. C., \& Demirtas, H. (2005). Learning with technology: The impact of laptop use on student achievement. The Journal of Technology, Learning, and Assessment, 3(2). Retrieved April 19, 2007, from http://webdev.shorelineschools.org/instruction/tech/pdf/jtla(1-1impact).pdf

Katz, Y., \& Offir, B. (1996). Hamoreh veshiluv hamaxshev behora'a [The teacher and integrating computers in teaching]. In Z. Mevarech \& N. Hativa (Eds.), Hamaxshev be'vet hasefer [Computers in school] (pp. 222-214). Jerusalem and Tel Aviv: Schocken.

Kozma, R.B. (2003). Technology and classroom practices: An international study. Journal of Research on Technology in Education, 36(1), 1-14. Retrieved July 11, 2010, from http://robertkozma.com/images/kozma_jrte.pdf

Lei, J., \& Zhao, Y. (2008). One-to-one computing: What does it bring to schools? Journal of Educational Computing Research, 39(2), 97-122.

Maine Education Policy Research Institute (MEPRI). (2003). The Maine learning technology initiative: Teacher, student, and school perspectives mid-year evaluation report. Retrieved November 6, 2003 from http://www.usm.maine.edu/cepare/pdf/ts/mlti.pdf 
Ministry of Education. (2012). Adapting the education system to the 21st century. National plan. Retrieved from http://cms.education.gov.il/EducationCMS/Units/MadaTech/hatamat_marechet_21/meyda_vepirsumi $\underline{\mathrm{m} /}$

Mioduser, D., Nachmias, R., Forkush, A., \& Tubin, D. (2003). Hadshanut hinuxit be'vatei sefer meshulavei tikshuv [Educational innovation in schools integrating ICT]. Research report IEA-OECD. Office of the Chief Scientist-Ministry of Education.

Mueller, J. (2009). Assessing critical skills. Columbus, OH: Linworth Publishing.

Penuel, W. R. (2006). Implementation and effects of one-to-one computing initiatives: A research synthesis. Journal of Research on Technology in Education 38(3), 329-348. Retrieved August 26, 2008, from http://www.eric.ed.gov/ERICDocs/data/ericdocs2sql/content_storage_01/0000019b/80/2a/5b/5b.pdf

Rockman et al. (1998). Powerful tools for schooling: Second year study of the laptop program. Retrieved from http://rockman.com/projects/126.micro.aal/yr2_report.pdf

Russell, M., Bebell, D., \& Higgins, J. (2004). Laptop learning: A comparison of teaching and learning in upper elementary classrooms equipped with shared carts of laptops and permanent 1:1 laptops. Boston, MA: Technology and Assessment Study Collaborative. Retrieved June 26, 2007, from http://www.intasc.org/PDF/Andover1 to1.pdf

Russell, M., Bebell, D., O‘Dwyer, L., \& O`Connor, K. (2003). Examining teacher technology use: Implications for preservice and inservice teacher preparation. Journal of Teacher Education, 54(4), 297-310.

Salomon, G. (2000). Technologia ve'hinuch be'idan hameida [Technology and education in the age of information]. Tel-Aviv University: Zmora-Bitan.

Shapley, K., Sheehan, D., Sturges, K., Caranikas-Walker, F., Huntsberger, B., \& Maloney, C. (2009). Evaluation of the Texas Technology Immersion Pilot: Final outcomes for a four-year study (2004-05 to 2007-08). Austin, TX: Texas Center for Educational Research.

Silvernail, D., \& Buffington, P. (2009). Improving mathematics performance using laptop technology: The importance of professional development for success. Gorham, ME: Maine Education Policy Research Institute.

Spektor-Levy, O., Eylon, B. S., \& Scherz, Z. (2009). Teaching scientific communication skills in science studies: Does it make a difference? International Journal of Science and Mathematics Education, 7(5), 875-903.

Swan, K., Van 'T Hooft, M., Kratcoski, A., \& Schenker, J. (2007). Ubiquitous computing and changing pedagogical possibilities: Representations, conceptualizations and uses of knowledge. Journal of Educational Computing Research, 36(4) 481-515.

Warschauer, M. (2005-2006). Going one-to-one. Educational Leadership, 63(4), 34-38. Retrieved from http://www.gse.uci.edu/person/warschauer_m/docs/going-1-to-1.pdf

Warschauer, M. (2008). Laptop and literacy: A multi-site case study. Pedagogies. An International Journal, 3(1), 52-67.

Weston, M. E., \& Bain, A. (2010). The end of techno-critique: The naked truth about 1:1 laptop initiatives and educational change. Journal of Technology, Learning, and Assessment, 9(6). Retrieved September 2011, from http://www.jtla.org

Zucker, A. A., \& Light, D. (2009). Laptop Programs for Students. Science, 323, 82-85. 


\section{Biographies}

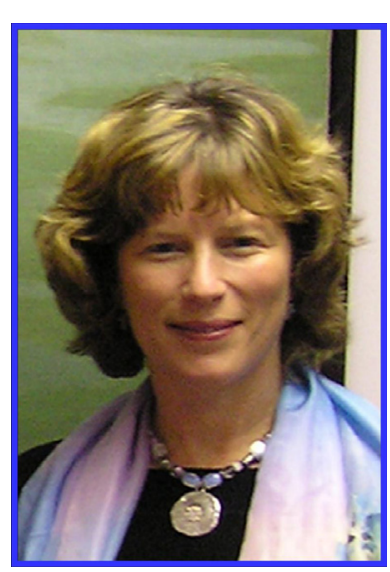

Ornit Spektor-Levy is a Lecturer in The School of Education at BarIlan University. Her field of interest is the impact of Information and Communication Technologies on teaching and learning. Main part of her studies examines the one-to-one class model. Another field of interest is Science \& Technology in inclusive classrooms, teachers' professional development; Science \& Technology education in pre-school ages.

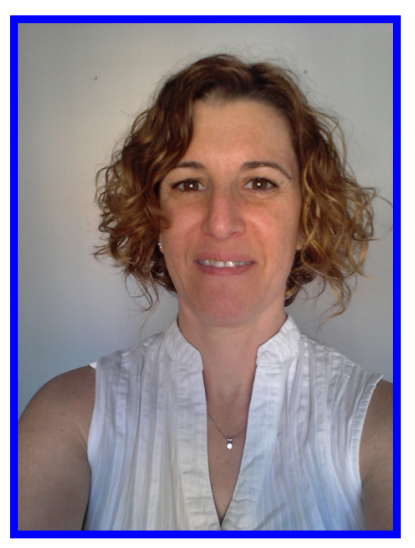

Yael Granot-Gilat is a Science \& Technology professional teacher in middle-school and high-school. This paper presents part of her study for Master degree in the School of Education, Bar Ilan University. 